\title{
PENGENDALIAN PERSEDIAAN BAHAN BAKU \\ PRODUK LP 29 B-STYLISH GT DENGAN PENDEKATAN MATERIAL REQUIREMENT PLANNING BERDASARKAN SILVER-MEAL DAN PART-PERIOD BALANCING
}

\author{
Suhartini ${ }^{(1)}$, Mochammad Basjir ${ }^{(2)}$ \\ Institut Teknologi Adhi Tama Surabaya, Universitas Islam Malang \\ suhartini@itats.ac.id,m.basjir@unisma.ac.id
}

\begin{abstract}
ABSTRAK
UD. Karya Jati merupakan perusahaan yang memproduksi panel seperti alamari, meja, rak tv dan pintu. setelah dilakukan analisa produk LP 29 B-Stylish GT merupakan produk make to stock memiliki permintaan yang paling tinggi. Saat ini perusahaan sering mengalami over stock disebabkan oleh kurang tepatnya perencanaan bahan baku yang diterapkan, dampak lain yang disebabkan adalah material terlalu lama berada di gudang yang berdampak pada tingginya holding cost. Untuk itu perlu dilakukan konsep perencanaan terhadap persediaan baha baku dalam rangka meminimalkan ketidaksesuaian tersebut dengan menggunakan metode Silver-Meal dan Part-Period Blancing. Tahap pertama yang dilakukan adalah peramalan terhadap permintaan produk karena adanya pola data yang horizontal maupun stationer dengan menggunakan metode Exponential Smoothing dan Moving Average. Setelah itu pembuatan Master Production Schedule (MPS) untuk perhitungan safety stock dari produk dilanjutkan pembuatan Material Requirement Planning (MRP) dari bahan baku digunakan untuk mendapatkan informasi tentang stock on hand dari material. Tahap akhir yang dilakukan adalah analisis terhadap biaya dari kedua metode tersebut, yaitu metode Silver-Meal dengan total inventory cost Rp 1.097.413.561 dan metode Part-Period Balancing sebesar Rp 1.097.468.136 dan membandingkan dari kedua metode itu pada perusahaan yang dimiliki total inventory cost Rp. 1.492.375.698. Hasil dari penelitian ini adalah Silver-Meal memiliki penghematan sebesar 35,99\% dibandingkan dengan Part-Period Balancing yang memiliki penghematan sebesar 35,98 \% dari kondisi existing perusahaan.
\end{abstract}

Kata Kunci : inventory cost, Material Requirement Planning, Silver Meal, Part Period Balancing

\section{PENDAHULUAN}

Persediaan (inventory) adalah salah satu elemen dalam modal kerja yang merupakan aktiva dalam keadaan berputar. Persediaan bahan baku cukup yaitu yang keberadaanya sesuai kebutuhan produksi, sehingga terjamin kelancaran dan kesinambungan produksi (Prima, 2014). Perusahaan harus memperhatikan adanya persediaan sebab persediaan adalah sumber daya menganggur (idle resources), bila overstock menjadi sia-sia namun bila kekurangan sulit mengantisipasi atau hal lainya yang menyebabkan terjadinya stockout (Mbota, 2014). Persediaan juga berpengaruh pada besar biaya operasi, sehingga kesalahan dalam pengelolaan persediaan akan merugikan perusahaan.

UD. Karya Jati merupakan perusahaan yang bergerak dalam bidang manufacturer of furniture bergerak pada produksi panel. Bahan baku yang digunakan UD. Karya Jati untuk proses produksi yaitu partikel board, medium density fibreboard (MDF), paper sheet, dan sparepart. Dalam produksi digunakan dua sistem salah satunya yaitu make-toorder produk yang banyak diminati adalah almari dua pintu atau L2P dengan kode produksi 29 BStylish GT dalam produksinya mengalami overstock dan stockout yang berakibat pada beralihnya konsumen ke produk dari perusahaan lain. Dalam meramalkan permintaan guna proses produksi berdasarkan hasil departemen marketing yang menganalisis pasar dan sales forecasting. Timbulnya holding cost disebabkan adanya persediaan bahan baku berlebih dan penumpukan persediaan produk. Selain itu pengembalian produk akibat kerusakan produk yang disebabkan penumpukan pun menjadi masalah yang dihadapi perusahaan.

Penelitian ini memberikan solusi optimal dalam pemenuhan kebutuhan, upaya yang dilakukan perusahaan dengan cara forecast permintaan menggunakan teknik time series dan melakukan pengendalian persediaan bahan baku guna proses produksi dan menentukan lot size produk yang perlu diproduksi secara terperinci. Pengendalian bahan baku dengan metode Material Requirement Planning (MRP) adalah suatu metode yang digunakan dalam merencanakan kebutuhan akan material didasarkan pada kebutuhan akan barang jadi. Ada Kaitan yang erat antara MRP dan 
lot sizing, yaitu lot size diartikan sebagai kuantitas komponen yang diproduksi di dalam industri manufaktur. Lot size sendiri adalah jumlah produksi, untuk komponen-komponen yang dibeli. Sedangkan dalam perencanaan kebutuhan lot sizing dihitung menggunakan dua metode yaitu metode Silver-Meal adalah metode yang dapat memberi nilai dalam biaya yang optimum untuk setiap pembelian ulang bahan baku (Mbota, 2014), dan metode PartPeriod Balancing (PPB) mencari periode rata-rata dimana antara biaya simpan dan biaya persediaan seimbang.

\section{METODE PENELITIAN}

Dalam penelitian ini akan dibahas tentang perencanaan pengadaan pesediaan pada nilai bahan baku, dengan pengoptimalan terhadap nilai persediaan bahan baku di gudang, dan juga meminimalkan nilai total biaya dari perusahaan dalam periode 9 bulan terhitung dimulai pada bulan Mei 2018 smpai dengan bulan Januari 2019. Untuk memahami mengenai setiap tahapan dalam penelitian ini, maka akan dijelaskan sebagai berikut :

\section{A. Tahap Identifikasi}

Tahap identifikasi bertujuan untuk menjelaskan mengenai latar belakang dibuatnya penelitian ini.

1. Perumusan Masalah

Bagian ini menjelaskan mengapa masalah itu perlu diteliti untuk mencari pemecahannya.

2. Menentuan tujuan dari penelitian

Penetapan tujuan penelitian didasarkan pada permasalahan yang telah diidentifikasikan.

3. Studi Kepustakaan

Studi kepustakaan sangat diperlukan untuk memperdalam pengetahuan teori atau metode-metode yang akan dipergunakan untuk memecahkan permasalahan.

4. Studi Lapangan

Studi lapangan dengan melakukan survei secara langsung agar diketahui secara nyata keadaan obyek yang diteliti. Obyek penelitian adalah UD. Karya Jati yang berlokasi di Jombang. Panel yang diamati adalah panel jenis almari dua pintu atau LP 29 B-Stylish GT.

\section{B. Tahap Pengumpulan Data}

Tahapan dalam mengumpulkan data merupakan aktifitas yang dilakukan dalam mendapatkan informasi dan data dari obyek serta mengumpulkan data yang diperlukan dalam penelitian. Data yang dikumpulkan meliputi:

1. Profil perusahaan.

2. Proses produksi produk LP 29 B-Stylish GT.

3. Data permintaan produk pada bulan Mei 2016 sampai April 2018.

4. Data lead time produk LP 29 B-Stylish GT.

5. Data harga bahan baku penyusun produk LP 29 BStylish GT. pada tahun 2018.
6. Data sisa persediaan atau stock-on-hand yang dimiliki perusahaan.

7. Data biaya pemesanan bahan baku produk LP 29 BStylish GT pada tahun 2018.

8. Data biaya penyimpanan untuk bahan baku produk LP 29 B-Stylish GT pada tahun 2018.

\section{Tahap Pengolahan Data}

Tahapan dalam pengolahan data adalah langkah yang diterapkan dalam menyelesaikan permasalahan yang terjadi.

\section{Melakukan peramalan}

1. Menganalisa terhadap adanya pola tertentu pada data historis dari permintaan produk almari dua pintu atau LP 29 B-Stylish GT yang didapatkan di UD. Karya Jati selama 2 tahun terakhir pada bulan Mei 2016 sampai bulan April 2018. Peralaman time series dengan software QM for Windows Versi 5.0.

2. Mengukur keakuratan hasil peramalan Mean Absolute Deviation (MAD) dan Mean Square Error (MSE) kemudian dianalisis hasil peramalan dengan error terkecil kemudian pengujian tracking signal.

\section{Metode Material Requirement Planning}

1. Pembuatan Master Production Schedule Membuat MPS guna perhitungan jumlah produk yang akan diproduksi.

2. Bill of Material (BOM)

Produk yang diteliti adalah produk jenis almari dua pintu atau LP 29 B-Stylish GT.

3. Melakukan perencanaan kebutuhan bahan baku produk LP 29 B-Stylish GT menggunakan Metode Material Requirement Planning (MRP).

\section{Teknik Lot sizing dan Menghitung Total Biaya yang} Diperlukan

Dalam penelitian ini ada dua metode yang diterapkan yaitu metode Silver-Meal, dan metode Part-Period Balancing $(P B B)$. Dari kedua metode ini akan ditetapkan kondisi dan dilakukan perbandingan bahwa dalam perhitungan nilai biaya yang dibutuhkan perusahaan dalam pemesanan bahan baku menggunakan konsep kedua metode tersebut.

\section{Tahap Analisa Data dan Pembahasan}

Dalam tahap ini akan dilakukan analisa terhadap hasil yang diperoleh dari proses pengolahan data. Analisa yang dilakukan membahas tentang metode forecasting yang optimum yang digunakan sesuai dengan pola data, pembuatan Material Requirement Planning (MRP) yang diusulkan, dan pembuatan lot sizing menggunakan metode Silver-Meal dan metode Part-Period Balancing kemudian di lakukan perbandingan terhadap total cost minimum dari hasil perbandingan dari metode yang diterapkan pada perusahaan.

\section{E. Tahap Kesimpulan dan Saran}

Tahapan terakhir dari analisa data dan pembahasan kemudian ditarik kesimpulan agar mudah dimengerti serta ringkas dari perumusan masalah dan tujuan. Selain itu juga dalam tahap ini penelitian dapat memberikan saran terhadap peneliti selanjutnya agar lebih baik. 


\section{HASIL DAN PEMBAHASAN}

\section{A. Peramalan}

Berdasarkan pola data historis permintaan produk adalah pola data horizontal, dimana nilai dari data akan berfluktuasi dengan nilai rata-rata yang konstan atau stasioner. Dengan diketahui pola maka peramalan yang sesuai adalah menggunakan metode eksponential smoothing dan metode moving average diantara metode yang ada dua metode tersebut adalah yang paling popular untuk peramalan jangka waktu singkat (Yager, 2013). Perhitungan peramalan menggunakan bantuan software QM for Windows Versi 5.0, hasilnya perbandingan nilai MAD dan MSE dilihat pada tabel 1. Nilai terkecil adalah metode eksponential smoothing yang kemudian diukur kembali menggunakan tracking signal terpilihlah metode eksponential smoothing 0,3 yang memiliki nilai negative dan positif yang seimbang.

Tabel 1. Perbandingan Nilai Error

\begin{tabular}{|l|c|c|c|c|}
\hline \multicolumn{1}{|c|}{$\begin{array}{c}\text { Metode } \\
\text { Peramalan }\end{array}$} & ME & MAD & MSE & MAPE \\
\hline $\begin{array}{l}\text { Exponential } \\
\text { Smoothing } \\
(0,1)\end{array}$ & 0,86 & 87,37 & 10435,12 & 11,4 \\
\hline $\begin{array}{l}\text { Exponential } \\
\text { Smoothing } \\
(0,2)\end{array}$ & 5,66 & 88,39 & 10961,59 & 11,48 \\
\hline $\begin{array}{l}\text { Exponential } \\
\text { Smoothing } \\
\text { (0,3) }\end{array}$ & 6,74 & 89,87 & 11579,51 & 11,66 \\
\hline $\begin{array}{l}\text { Moving } \\
\text { Average } \\
\text { (3MA) }\end{array}$ & 13,27 & 102,48 & 15218,93 & 13,26 \\
\hline $\begin{array}{l}\text { Moving } \\
\text { Average } \\
\text { (4MA) }\end{array}$ & 6,85 & 92,73 & 12719,66 & 12,18 \\
\hline
\end{tabular}

\section{B. Jadwal Induk Produksi (MPS)}

Setelah mendapatkan hasil nilai peramalan untuk 9 bulan kedepan, hasil nilai peramalan tersebut akan digunakan dalam pembuatan MPS yang terbagi dalam periode 4 minggu, sehingga akan didapat 36 periode dalam satuan minggu. Berikut contoh langkah pembuatan MPS :

1. Hasil perhitungan safety stock yang didapat dari hasil peramalan akan ditambahkan. Safety stock yang digunakan adalah safety stock produk.

2. Perhitungan kebutuhan produk LP 29 B-Stylish GT disesuaikan dengan kebijakan perusahaan, dimana untuk minggu pertama di bulan Mei
2018 diproduksi di bulan sebelumnya sehingga kebutuhan bulan Mei 2018 dibagi dengan 3 dan dimasukkan pada minggu ke 2,3 dan 4 menjadi produksi pada minggu ke 1,2 dan 3 bulan Mei 2018 dan bulan berikutnya akan dibagi dengan 4 sesui periode mingguan.

3. Perhitungan projected available balance menunjukkan total sisa persediaan atau stock on hand produk. Perusahaan memiliki persediaan sebesar 280 unit box.

\section{Material Requirement Planning}

Dasar pembuatan material requirement planning dengan menggunakan MPS sehingga hasil perhitungannya digunakan untuk input dari MRP. Perhitungan material engsel dapat dilihat pada tabel 2.

\section{Biaya Simpan dan Biaya Pemesanan}

Biaya yang diperlukan antara lain biaya pemesanan atau ordering cost untuk satu kali pemesanan, biaya pemesanan tidak melihat berapa banyak produk yang dipesan. Sedangkan biaya penyimpanan (holding cost) dalam gudang. Biaya penyimpanan yang diterapkan gudang UD. Karya Jati yaitu mencakup biaya resiko kerusakan barang, dan biaya pajak dan asuransi yang besarnya tiap komponen yang dibeli berbeda.

Tabel 2. Biaya Penyimpanan dan Biaya Pemesanan

\begin{tabular}{|c|c|c|c|c|}
\hline Komponen & $\begin{array}{l}\text { Harga Satuan } \\
\text { Unit }\end{array}$ & & $\begin{array}{l}\text { iaya } \\
\text { mpan }\end{array}$ & Biaya Pesan \\
\hline Engsel & $\mathrm{Rp} 40.000$ & $\mathrm{Rp}$ & 400 & $\mathrm{Rp} \quad 327.550$ \\
\hline Sekrup & Rp 10.000 & $\mathrm{Rp}$ & 40 & Rp 137.690 \\
\hline Kunci & Rp 20.000 & $\mathrm{Rp}$ & 200 & Rp 300.000 \\
\hline Kaca & Rp 28.300 & $\mathrm{Rp}$ & 849 & Rp 500.000 \\
\hline Handle & Rp 16.990 & $\mathrm{Rp}$ & 170 & Rp 327.550 \\
\hline $\begin{array}{l}\text { Karton } \\
\text { Box } \\
\end{array}$ & Rp 19.300 & $\mathrm{Rp}$ & 965 & Rp 320.000 \\
\hline Edging & Rp 330.000 & $\mathrm{Rp}$ & 3.300 & Rp 395.000 \\
\hline $\begin{array}{l}\text { Paper } \\
\text { Sheet } \\
\text { Amano }\end{array}$ & Rp 3.500 .000 & $\mathrm{Rp}$ & 25.000 & Rp 875.000 \\
\hline $\begin{array}{l}\text { Paper } \\
\text { Sheet } \\
\text { Walnut }\end{array}$ & Rp 3.529 .000 & $\mathrm{Rp}$ & 25.000 & Rp 875.000 \\
\hline MDF & $\mathrm{Rp} \quad 180.000$ & $\mathrm{Rp}$ & 9.000 & Rp 800.000 \\
\hline $\begin{array}{l}\text { Partikel } \\
\text { Board }\end{array}$ & $\mathrm{Rp} \quad 160.000$ & $\mathrm{Rp}$ & 8.000 & Rp 800.000 \\
\hline Frame & $\mathrm{Rp} \quad 20.000$ & $\mathrm{Rp}$ & 1.600 & Rp 137.550 \\
\hline Hang & 5.860 & $\mathrm{Rp}$ & 59 & Rp 137.550 \\
\hline Mahkota & 2.450 & $\mathrm{Rp}$ & 25 & Rp 100.000 \\
\hline Kaki & 2.500 & $\mathrm{Rp}$ & 25 & Rp 100.000 \\
\hline Perekat & Rp 990.834 & $\mathrm{Rp}$ & 150 & Rp 150.000 \\
\hline
\end{tabular}

Sumber: Bagian Gudang Perusahaan 
Tabel 3. Master Production Schedule Produk LP 29 B-Stylish GT

\begin{tabular}{|c|c|c|c|c|c|c|c|c|c|c|c|c|c|}
\hline \multirow{2}{*}{\multicolumn{2}{|c|}{ Periode }} & \multicolumn{4}{|c|}{ Mei 2018} & \multicolumn{4}{|c|}{ Juni 2018} & \multicolumn{4}{|c|}{ Juli 2018} \\
\hline & & 1 & 2 & 3 & 4 & 5 & 6 & 7 & 8 & 9 & 10 & 11 & 12 \\
\hline Forecast & & 274 & 274 & 274 & 198 & 198 & 198 & 198 & 195 & 195 & 195 & 195 & 210 \\
\hline Projected Available Balance & 280 & 216 & 152 & 89 & 100 & 112 & 124 & 135 & 150 & 165 & 180 & 195 & 195 \\
\hline \multicolumn{2}{|l|}{$M P S$} & 210 & 210 & 210 & 210 & 210 & 210 & 210 & 210 & 210 & 210 & 210 & 210 \\
\hline & & \multicolumn{4}{|c|}{ Agustus 2018} & \multicolumn{4}{|c|}{ September 2018} & \multicolumn{4}{|c|}{ Oktober 2018} \\
\hline \multicolumn{2}{|l|}{ Periode } & 13 & 14 & 15 & 16 & 17 & 18 & 19 & 20 & 21 & 22 & 23 & 24 \\
\hline \multicolumn{2}{|l|}{ Forecast } & 210 & 210 & 210 & 197 & 197 & 197 & 197 & 193 & 193 & 193 & 193 & 187 \\
\hline \multicolumn{2}{|l|}{ Projected Available Balance } & 195 & 195 & 195 & 208 & 11 & 23 & 36 & 53 & 70 & 88 & 105 & 128 \\
\hline \multicolumn{2}{|l|}{$M P S$} & 210 & 210 & 210 & 210 & & 210 & 210 & 210 & 210 & 210 & 210 & 210 \\
\hline & & \multicolumn{4}{|c|}{ November 2018} & \multicolumn{4}{|c|}{ Desember 2018} & \multicolumn{4}{|c|}{ Januari 2018} \\
\hline Periode & & 25 & 26 & 27 & 28 & 29 & 30 & 31 & 32 & 33 & 34 & 35 & 25 \\
\hline Forecast & & 187 & 187 & 187 & 194 & 194 & 194 & 194 & 195 & 195 & 195 & 195 & 187 \\
\hline Projected Available Balance & & 150 & 173 & 196 & 1 & 17 & 33 & 48 & 64 & 79 & 94 & 109 & 150 \\
\hline$M P S$ & & 210 & 210 & 210 & & 210 & 210 & 210 & 210 & 210 & 210 & 210 & 210 \\
\hline
\end{tabular}

Tabel 4. Material Requirement Planning Material Engsel

\begin{tabular}{|c|c|c|c|c|c|c|c|c|c|c|c|c|c|c|}
\hline \multirow{2}{*}{\multicolumn{2}{|c|}{$\begin{array}{c}\text { Item }: \text { ENGSEL } \\
\text { LZ }: 200 \\
\text { LT }: 1\end{array}$}} & & \multicolumn{4}{|c|}{ Mei 2018} & \multicolumn{4}{|c|}{ Juni 2018} & \multicolumn{4}{|c|}{ Juli 2018} \\
\hline & & 4 & 1 & 2 & 3 & 4 & 5 & 6 & 7 & 8 & 9 & 10 & 11 & 12 \\
\hline Gross Require & & & 560 & 840 & 840 & 840 & 840 & 840 & 840 & 840 & 840 & 840 & 840 & 840 \\
\hline \multicolumn{15}{|c|}{ Scheduled Receipts } \\
\hline $\begin{array}{l}\text { Projected On } \\
\text { Hand }\end{array}$ & 180 & & 20 & 180 & 140 & 100 & 60 & 20 & 180 & 340 & 300 & 60 & 20 & 180 \\
\hline \multicolumn{2}{|c|}{ Net Requirements } & & 380 & 820 & 660 & 700 & 740 & 780 & 820 & 660 & 500 & 540 & 780 & 820 \\
\hline \multicolumn{2}{|c|}{ Planned Order Receipts } & & 400 & 1000 & 800 & 800 & 800 & 800 & 1000 & 1000 & 800 & 600 & 800 & 1000 \\
\hline \multicolumn{2}{|c|}{ Planned Order Release } & 400 & 1000 & 800 & 800 & 800 & 800 & 1000 & 1000 & 800 & 600 & 800 & 1000 & 800 \\
\hline \multirow{2}{*}{\multicolumn{2}{|c|}{$\begin{array}{c}\text { Item }: \text { ENGSEL } \\
\text { LZ }: 200 \\
\text { LT }: 1\end{array}$}} & & \multicolumn{4}{|c|}{ Agustus 2018} & \multicolumn{4}{|c|}{ September 2018} & \multicolumn{4}{|c|}{ Oktober 2018} \\
\hline & & & 13 & 14 & 15 & 16 & 17 & 18 & 19 & 20 & 12 & 22 & 23 & 24 \\
\hline Gross Require & & & 840 & 840 & 840 & & 840 & 840 & 840 & 840 & 840 & 840 & 840 & 840 \\
\hline \multicolumn{15}{|c|}{ Scheduled Receipts } \\
\hline \multicolumn{2}{|c|}{ Projected On Hand } & & 140 & 100 & 60 & 60 & 20 & 180 & 140 & 100 & 60 & 20 & 180 & 140 \\
\hline \multicolumn{2}{|c|}{ Net Requirements } & & 660 & 700 & 740 & & 780 & 820 & 660 & 700 & 740 & 780 & 820 & 660 \\
\hline \multicolumn{2}{|c|}{ Planned Order Receipts } & & 800 & 800 & 800 & 0 & 800 & 1000 & 800 & 800 & 800 & 800 & 1000 & 800 \\
\hline \multicolumn{2}{|c|}{ Planned Order Release } & & 800 & 800 & & 800 & 1000 & 800 & 800 & 800 & 800 & 1000 & 800 & 800 \\
\hline \multirow{2}{*}{\multicolumn{2}{|c|}{$\begin{array}{c}\text { Item }: \text { ENGSEL } \\
\text { LZ }: 200 \\
\text { LT }: 1\end{array}$}} & & \multicolumn{4}{|c|}{ November 2018} & \multicolumn{4}{|c|}{ Desember 2018} & \multicolumn{4}{|c|}{ Januari 2019} \\
\hline & & & 25 & 26 & 27 & 28 & 29 & 30 & 31 & 32 & 33 & 34 & 35 & 36 \\
\hline Gross Require & & & 840 & 840 & & 840 & 840 & 840 & 840 & 840 & 840 & 840 & & \\
\hline \multicolumn{15}{|c|}{ Scheduled Receipts } \\
\hline Projected On $\mathrm{I}$ & & & 100 & 60 & 60 & 20 & 180 & 140 & 100 & 60 & 20 & 180 & & \\
\hline Net Requireme & & & 700 & 740 & & 780 & 820 & 660 & 700 & 740 & 780 & 820 & & \\
\hline Planned Order & eceipts & & 800 & 800 & & 800 & 1000 & 800 & 800 & 800 & 800 & 1000 & & \\
\hline Planned Order & elease & & 800 & & 800 & 1000 & 800 & 800 & 800 & 800 & 1000 & & & \\
\hline
\end{tabular}

\section{Metode Silver Meal}

Perhitungan lot sizing dengan teknik untuk meminimasi ongkos total per periode. Berikut contoh perhitungan untuk material engsel. Material ini merupakan material yang lead time pembeliannya 1 minggu terdapat beberapa supplier yang biasa melakukan supply ke UD. Karya Jati melihat berapa lama dan keberadaan stok produknya untuk minimal pembeliannya 400 unit engsel. Biaya pesan sebesar $\mathrm{Rp} 327.550$, biaya simpan sebesar Rp 400, permintaan produk periode 1 adalah 400 Unit.

$$
\begin{gathered}
\operatorname{TRC}(\mathrm{T})=\frac{\mathrm{C}+\mathrm{Ph} \sum_{\mathrm{k}=1}^{\mathrm{T}}(\mathrm{k}-1) \mathrm{R}_{\mathrm{k}}}{\mathrm{T}} \\
\operatorname{TRC}(\mathrm{T})=\frac{327.550+(400((1-1) x 400))}{1} \\
\operatorname{TRC}(\mathrm{T})=\frac{327.550+(0)}{1} \\
\operatorname{TRC}(\mathrm{T})=\operatorname{Rp} 327.550
\end{gathered}
$$


Dapat disimpulkan total biaya relevan periode $\mathrm{T}=1$ sebesar Rp. 327.550. langkah selanjutnya untuk periode $\mathrm{T}=2$ dengan biaya pemesanan dan biaya penyimpanan yang sama tetapi permintaan sebesar 1.000 Unit.

$$
\begin{aligned}
& \operatorname{TRC}(\mathrm{T}) \\
& =\frac{327.550+(400(((1-1) x 400)+((2-1) 1000)))}{2} \\
& \operatorname{TRC}(\mathrm{T})=\frac{397.550+(4000)}{2} \\
& \operatorname{TRC}(\mathrm{T})=\frac{727.550}{2} \\
& \operatorname{TRC}(\mathrm{T})=\operatorname{Rp} 363.775
\end{aligned}
$$

Dapat disimpulkan total biaya relevan periode $\mathrm{T}=2$ sebesar Rp. 363.775. Setelah menghitung kombinasi biaya terhadap periode 1 dan periode 2 , dilakukan juga perbandingan terhadap total biaya per periodenya pada tiap-tiap kombinasinya. Dari hasil perhitungan total biaya kombinasi pada periode TRC(1) < TRC(2) atau Rp. $327.550<$ Rp.

\begin{tabular}{|c|c|c|c|}
\hline $\begin{array}{l}\text { Kombinasi } \\
\text { Periode }\end{array}$ & $\begin{array}{l}\text { Jumlah } \\
\text { order } \\
\text { (Unit) }\end{array}$ & $\begin{array}{c}\text { Biaya } \\
\text { Kumulatif }\end{array}$ & $\begin{array}{c}\text { Rata-rata } \\
\text { Total Biaya } \\
\text { per Periode }\end{array}$ \\
\hline $1 *$ & 400 & $\mathrm{Rp} \quad 327.550$ & Rp 327.550 \\
\hline 1,2 & 1000 & $\mathrm{Rp} \quad 727.550$ & Rp 363.775 \\
\hline 2 & 1000 & $\mathrm{Rp} \quad 327.550$ & Rp 327.550 \\
\hline $2,3^{*}$ & 800 & Rp $\quad 647.550$ & Rp 323.775 \\
\hline $2,3,43$ & 800 & $\mathrm{Rp} 1.287 .550$ & $\operatorname{Rp} 429.183$ \\
\hline 4 & 800 & $\mathrm{Rp} \quad 327.550$ & Rp 327.550 \\
\hline $4,5^{*}$ & 800 & $\mathrm{Rp} \quad 647.550$ & Rp 323.775 \\
\hline $4,5,6$ & 800 & Rp 1.287.550 & $\operatorname{Rp} 429.183$ \\
\hline $6^{*}$ & 800 & $\mathrm{Rp} \quad 327.550$ & Rp 327.550 \\
\hline 6,7 & 1000 & Rp 727.550 & Rp 363.775 \\
\hline $7 *$ & 1000 & $\mathrm{Rp} \quad 327.550$ & Rp 327.550 \\
\hline 7,8 & 1000 & $\mathrm{Rp} \quad 727.550$ & Rp 363.775 \\
\hline 8 & 1000 & $\mathrm{Rp} \quad 327.550$ & Rp 327.550 \\
\hline $8,9^{*}$ & 800 & $\mathrm{Rp} \quad 647.550$ & Rp 323.775 \\
\hline $8,9,10$ & 600 & Rp 1.127.550 & Rp 375.850 \\
\hline 10 & 600 & $\mathrm{Rp} \quad 327.550$ & Rp 327.550 \\
\hline $10,11 *$ & 800 & $\mathrm{Rp} \quad 647.550$ & Rp 323.775 \\
\hline
\end{tabular}
363.775. bisa dinyatakan bahwa periode optimal adalah periode 1 .

Tabel 5. Pemesanan Menggunakan Silver-Meal Material Engsel

(Keterangan: * periode optimal)
Berdasarkan tabel diatas, pemesanan material engsel yang dilakukan untuk pemenuhan material yang dibutuhkan untuk proses produksi 9 bulan kedepan mengunakan metode Silver-Meal dilakukan sebanyak 19 kali pada periode $1,2,4,6,7,8,10$. Pengombinasian periode dilakukan sampai akhir periode atau periode ke 36 .

Melakukan perhitungan inventory cost dengan tiga persamaan 2.20, 2.21, dan 2.22 dari metode Silver-Meal, yang dihitung adalah total biaya pemesanan dan total biaya penyimpanan material

\begin{tabular}{|c|c|c|c|c|}
\hline Material & $\begin{array}{c}\text { Frekuensi } \\
\text { Pemesan }\end{array}$ & $\begin{array}{l}\text { Total Biaya } \\
\text { Pemesanan }\end{array}$ & $\begin{array}{c}\text { Total Biaya } \\
\text { Simpan }\end{array}$ & Inventory Cost \\
\hline Engsel & 19 & Rp 6.223.450 & Rp 5.968.000 & Rp 12.191 .450 \\
\hline Sekrup & 9 & Rp 1.239.210 & Rp14.040.000 & Rp 15.279 .210 \\
\hline Kunci & 11 & Rp 3.300.000 & Rp 2.810.000 & Rp 6.110 .000 \\
\hline Kaca & 16 & Rp 8.000.000 & Rp 4.754.400 & Rp 12.754 .400 \\
\hline Handel & 11 & Rp 3.603.050 & Rp 2.500 .928 & Rp 6.103 .978 \\
\hline $\begin{array}{l}\text { Karton } \\
\text { Box }\end{array}$ & 17 & Rp 5.440.000 & Rp 3.203.800 & Rp 8.643 .800 \\
\hline Edging & 9 & Rp 3.577.500 & Rp 2.301.316 & Rp 5.878.816 \\
\hline $\begin{array}{l}\text { Paper } \\
\text { Sheet } \\
\text { Amano }\end{array}$ & 31 & Rp27.125.000 & Rp11.025.000 & Rp 38.150 .000 \\
\hline $\begin{array}{l}\text { Paper } \\
\text { Sheet } \\
\text { Walnut }\end{array}$ & 5 & Rp 4.375.000 & Rp 3.856.809 & Rp 8.231.809 \\
\hline MDF & 5 & Rp 4.000.000 & kp 301.050.000 & Rp 305.050.000 \\
\hline $\begin{array}{l}\text { Partikel } \\
\text { Board }\end{array}$ & 7 & Rp 5.600.000 & kp 656.800.000 & Rp 662.400 .000 \\
\hline Frame & 30 & Rp 4.126.500 & $\operatorname{Rp} \quad 1.680 .000$ & Rp 5.806 .500 \\
\hline Hang & 7 & Rp 962.850 & Rp $\quad 879.000$ & Rp 1.841.850 \\
\hline Mahkota & 6 & Rp $\quad 600.000$ & Rp 1.046.248 & Rp 1.646 .248 \\
\hline Kaki & 6 & Rp $\quad 600.000$ & Rp 2.140.000 & Rp 2.740 .000 \\
\hline Perekat & 16 & Rp 2.400.000 & Rp 2.185.500 & Rp 4.585 .500 \\
\hline \multicolumn{2}{|c|}{ Total } & $\begin{array}{c}\text { Rp81.172.56 } \\
0\end{array}$ & $\begin{array}{c}\text { Rp1.016.241.00 } \\
1\end{array}$ & $\begin{array}{c}\mathrm{Rp} \\
1.097 .413 .561\end{array}$ \\
\hline
\end{tabular}
yang dibutuhkan untuk proses produksi. Perhitungan material engsel sebagai berikut:

Tabel 6. Perhitungan Inventory Cost menggunakan metode Silver-Meal

\section{Metode Part-Period Balancing}

Perhitungan lot sizing dilaksanakan dengan kumulasi permintaan. Langkah pertama mengkonversikan biaya pemesanan menjadi Economic Part Period (EPP), EPP merupakan kuantitas pembelian yang menyeimbangkan biaya pemesanan dan biaya penyimpanan berdasarkan komulatif part period. Dihitung dengan 2.18. Mencari nilai EPP material, setelah mendapatkan nilai EPP yang akan menjadi kebutuhan dan 
diakumulasikan pada setiap periode sampai mendekati nilai EPP. Nilai akumulasi persedian yang mendekati nilai EPP tersebut adalah ukuran jumlah lot yang akan dipilih dan nantinya akan dapat memperkecil biaya dari persediaan. Berikut contoh langkah pengerjaan metode Part-Period Balancing dengan material engsel.

$$
\begin{gathered}
\mathrm{EPP}=\frac{S}{\mathrm{~h}} \\
\mathrm{EPP}=\frac{R p \cdot 327.550}{\mathrm{Rp} \cdot 400} \\
\mathrm{EPP}=819 \text { Unit per period }
\end{gathered}
$$

Nilai lot sizing yang digunakan untuk material engsel adalah 819 unit per periodenya, bila EPP tidak memenuhi atau melebihi pemilihan dilakukan dengan nilai mendekati.

Berikut tabel hasil perhitungan dengan langkah yang sama untuk material engsel sedangkan untuk material lainnya dilampirkan.

Tabel 7. Pemesanan Menggunakan Metode PartPeriod Balancing Material Engsel

\begin{tabular}{|c|c|c|l|c|}
\hline $\begin{array}{l}\text { Kombinasi } \\
\text { Periode }\end{array}$ & $\begin{array}{l}\text { Jumlah } \\
\text { Order } \\
\text { (Unit) }\end{array}$ & $\begin{array}{l}\text { Lot Size } \\
\text { Kumulatif }\end{array}$ & $\begin{array}{l}\text { Inventory } \\
\text { Period }\end{array}$ & $\begin{array}{l}\text { Accumulated } \\
\text { Part-Period }\end{array}$ \\
\hline 1 & 400 & 400 & 0 & 0 \\
\hline $1,2^{*}$ & 1.000 & 1.400 & 1 & 1.000 \\
\hline $1,2,3$ & 800 & 2.200 & 2 & 2.600 \\
\hline 3 & 800 & 800 & 0 & 0 \\
\hline $3,4^{*}$ & 800 & 1.600 & 1 & 800 \\
\hline $3,4,5$ & 800 & 2.400 & 2 & 2.400 \\
\hline 5 & 800 & 800 & 0 & 800 \\
\hline $5,6^{*}$ & 800 & 1.600 & 1 & 2.800 \\
\hline $5,6,7$ & 1.000 & 2.600 & 2 & 0 \\
\hline 7 & 1.000 & 1.000 & 0 & 1.000 \\
\hline $7,8^{*}$ & 1.000 & 2.000 & 1 & 2.600 \\
\hline $7,8,9$ & 800 & 2.800 & 2 & 0 \\
\hline 9 & 800 & 800 & 0 & 1 \\
\hline $9,10^{*}$ & 600 & 1.400 & & 000 \\
\hline$(K e t e r a n g a n *$ & $p e r i 0 d$ & $0 p t i m a 1)$ & & 0 \\
\hline
\end{tabular}

(Keterangan: * periode optimal)

Berdasarkan tabel diatas, pemesanan material engsel yang dilakukan untuk pemenuhan material yang dibutuhkan untuk proses produksi 9 bulan kedepan menggunakan metode Part-Period Balancing dilakukan sebanyak 16 kali pada periode $1,3,5,7,9$. Pengombinasian periode dilakukan sampai akhir periode atau periode ke 36 .
Melakukan perhitungan inventory cost dengan tiga persamaan 2.20, 2.21, dan 2.22 dari metode Part-Period Balancing, yang dihitung adalah total biaya pemesanan dan total biaya penyimpanan material yang dibutuhkan untuk proses produksi. Perhitungan untuk material engsel sebagai berikut:

Tabel 8. Perhitungan Inventory Cost menggunakan

\begin{tabular}{|c|c|c|c|c|}
\hline Material & $\begin{array}{l}\text { Frekuensi } \\
\text { Pemesanan }\end{array}$ & $\begin{array}{l}\text { Total Biaya } \\
\text { Pemesanan }\end{array}$ & $\begin{array}{c}\text { Total Biaya } \\
\text { Simpan }\end{array}$ & Inventory Cost \\
\hline Engsel & 16 & Rp 5.240 .800 & Rp 7.568.000 & $\mathrm{Rp} \quad 12.808 .800$ \\
\hline Sekrup & 9 & Rp 1.239 .210 & Rp 16.056 .000 & Rp $\quad 17.295 .210$ \\
\hline Kunci & 11 & Rp 3.300 .000 & $\mathrm{Rp} \quad 2.900 .000$ & Rp $\quad 6.200 .000$ \\
\hline Kaca & 11 & Rp 5.500 .000 & Rp 7.046 .700 & $\mathrm{Rp} \quad 12.546 .700$ \\
\hline Handel & 9 & Rp 2.947 .950 & Rp $\quad 3.231 .498$ & Rp $\quad 6.179 .448$ \\
\hline $\begin{array}{l}\text { Karton } \\
\text { Box }\end{array}$ & 16 & Rp 5.120 .000 & Rp 3.811 .750 & Rp 8.931 .750 \\
\hline Edging & 6 & $\mathrm{Rp} 2.385 .000$ & $\mathrm{Rp} \quad 3.311 .116$ & $\mathrm{Rp} \quad 5.696 .116$ \\
\hline $\begin{array}{l}\text { Paper } \\
\text { Sheet } \\
\text { Amano }\end{array}$ & 17 & Rp 14.875 .000 & Rp $\quad 19.677 .105$ & Rp $\quad 34.552 .105$ \\
\hline $\begin{array}{l}\text { Paper } \\
\text { Sheet } \\
\text { Walnut }\end{array}$ & 5 & Rp 4.375 .000 & Rp $\quad 3.856 .809$ & Rp 8.231 .809 \\
\hline$M D F$ & 5 & Rp 4.000 .000 & Rp 301.050.000 & Rp 305.050 .000 \\
\hline $\begin{array}{l}\text { Partikel } \\
\text { Board }\end{array}$ & 7 & Rp 5.600 .000 & Rp 656.800.000 & $\mathrm{Rp} 662.400 .000$ \\
\hline Frame & 30 & Rp 4.126 .500 & $\mathrm{Rp} \quad 1.680 .000$ & $\mathrm{Rp} \quad 5.806 .500$ \\
\hline Hang & 5 & Rp 687.750 & $\mathrm{Rp} \quad 1.142 .700$ & $\mathrm{Rp} \quad 1.830 .450$ \\
\hline Mahkota & 6 & Rp 600.000 & $\mathrm{Rp} \quad 1.046 .248$ & Rp $\quad 1.646 .248$ \\
\hline Kaki & 6 & Rp 600.000 & Rp $\quad 2.140 .000$ & Rp 2.740 .000 \\
\hline Perekat & 8 & Rp 1.200 .000 & Rp 4.353 .000 & Rp 5.553 .000 \\
\hline \multicolumn{2}{|c|}{ Total } & $\mathrm{Rp} 61.797 .210$ & Rp1.035.670.926 & Rp 1.097.468.136 \\
\hline
\end{tabular}
metode Part-Period Balancing Material Penyusun Produk

\section{Perhitungan Inventory Cost dengan Metode Perusahaan Existing}

Dengan memperhitungkan kebutuhan produksi perusahaan untuk tiga bulan ke depan, perusahaan belum menerapkan perencanaan dan persediaan yang baik atau perencanaan dilakukan secara tradisional selain perencanaan pemesanan proses peramalan juga dilakukan dengan koordinasi antara marketing, PPIC, manager operasional dan direktur. Perencanaan kebutuhan bahan baku produk LP 29 B-Stylish GT untuk 9 bulan kedepan dapat dilihat pada tabel berikut. 
Tabel 9. Perencanaan kebutuhan bahan baku produk LP 29 B-Stylish GT

\begin{tabular}{|c|c|c|c|c|c|}
\hline $\begin{array}{c}\text { Jenis } \\
\text { Materil }\end{array}$ & $\begin{array}{c}\text { Frekuensi } \\
\text { Pemesanan }\end{array}$ & $\begin{array}{l}\text { Total Biaya } \\
\text { Pemesanan }\end{array}$ & $\begin{array}{c}\text { Total Biaya } \\
\text { Simpan }\end{array}$ & \multicolumn{2}{|c|}{ Inventory Cost } \\
\hline Engsel & 3 & Rp 982.650 & Rp 39.264 .000 & $\mathrm{Rp}$ & 40.246 .650 \\
\hline Sekrup & 3 & Rp 413.070 & Rp 30.304 .000 & $\mathrm{Rp}$ & 30.717 .070 \\
\hline Kunci & 3 & Rp 900.000 & Rp $\quad 9.156 .000$ & $\mathrm{Rp}$ & 10.056 .000 \\
\hline Kaca & 3 & Rp 1.500 .000 & Rp 17.311 .110 & $\mathrm{Rp}$ & 18.811 .110 \\
\hline Handel & 3 & Rp 982.650 & Rp 7.224.148 & $\mathrm{Rp}$ & 8.206 .798 \\
\hline $\begin{array}{l}\text { Karton } \\
\text { Box }\end{array}$ & 3 & Rp 960.000 & Rp 20.149.200 & $\mathrm{Rp}$ & 21.109 .200 \\
\hline Edging & 3 & Rp 1.192 .500 & Rp $\quad 4.605 .237$ & $\mathrm{Rp}$ & 5.797 .737 \\
\hline $\begin{array}{l}\text { Paper } \\
\text { Sheet } \\
\text { Amano }\end{array}$ & 3 & Rp 2.625.000 & Rp196.444.559 & $\mathrm{Rp}$ & 199.069.559 \\
\hline $\begin{array}{l}\text { Paper } \\
\text { Sheet } \\
\text { Walnut }\end{array}$ & 3 & Rp 2.625.000 & $\mathrm{Rp} \quad 4.715 .759$ & $\mathrm{Rp}$ & 7.340 .759 \\
\hline MDF & 3 & $\mathrm{Rp} 2.400 .000$ & Rp241.920.000 & $\mathrm{Rp}$ & 244.320 .000 \\
\hline $\begin{array}{l}\text { Partike } \\
\text { l Board }\end{array}$ & 3 & Rp 2.400 .000 & Rp847.600.000 & $\mathrm{Rp}$ & 850.000 .000 \\
\hline Frame & 3 & Rp 412.650 & Rp 38.640 .000 & $\mathrm{Rp}$ & 39.052 .650 \\
\hline Hang & 3 & Rp 412.650 & $\mathrm{Rp} \quad 1.288 .028$ & $\mathrm{Rp}$ & 1.700 .678 \\
\hline $\begin{array}{l}\text { Mahkot } \\
\text { a }\end{array}$ & 3 & Rp 300.000 & $\mathrm{Rp} \quad 1.573 .488$ & $\mathrm{Rp}$ & 1.873 .488 \\
\hline Kaki & 3 & Rp 300.000 & $\mathrm{Rp} \quad 2.792 .500$ & $\mathrm{Rp}$ & 3.092 .500 \\
\hline Perekat & 3 & Rp 450.000 & Rp 10.531.500 & $\mathrm{Rp}$ & 10.981 .500 \\
\hline \multicolumn{2}{|c|}{ Total } & Rp 18.856 .170 & $\begin{array}{l}\mathrm{Rp} \\
1.473 .519 .528\end{array}$ & \multicolumn{2}{|c|}{ Rp 1.492.375.698 } \\
\hline
\end{tabular}

\section{Perbandingan Hasil Metode Lot Sizing}

Tujuan dalam melakukan perbandingan terhadap metode yang diterapkan adalah dapat diketahui secara pasti metode apa yang dapat menghasilkan perhitungan biaya yang minimal dalam pemenuhan kebutuhan terhadap bahan baku dan pemenuhan kebutuhan produksi yang optimal. Perhitungan total biaya dalam metode ini adalah nilai simpanan dari biaya dan nilai pemesanan dari biaya. Perbandingan dilakukan dengan mencari nilai total dari biaya dari masing-masing metode pada tiap-tiap jenis material. Perbandingan total biaya atau inventory cost untuk Metode Silver-Meal sebesar Rp 1.097.413.561, Metode Part-Period Balancing sebesar Rp 1.097.468.136, dan Metode exsisting perusahaan sebesar Rp 1.492.375.698. sehingga Metode Silver-Meal merupakan metode dengan biaya paling minimum.

\section{PENUTUP}

1. Setelah melakukan peramalan dengan menggunakan software QM for Windows Versi 5.0 pada kebutuhan produk LP 29 B-Staylish GT. Metode peramalan Exponential Smoothing terpilih karena menghasilkan peramalan optimal dengan nilai MSE terendah dibandingkan metode peramalan Moving Average. Kemudian pengujian nilai error dilakukan dengan teknik tracking signal kemudian terpilih metode peramalan Exponential Smoothing 0,3 yang nilai negative dan positif error seimbang. Sehingga peramalan produk menggunakan metode Exponential Smoothing 0,3. Hasil forecast dimulai pada bulan Mei 2018 sebanyak 791 unit box, Juni 2018 sebanyak 763 unit box, Juli 2018 sebanyak 750 unit box, Agustus 2018sebanyak 809 unit box, September 2018 sebanyak 759 unit box, Oktober 2018 sebanyak 741 unit box, November 2018 sebanyak 719 unit box, Desember 2018 sebanyak 747 unit box, Januari 2019 sebanyak 748 unit box.

2. Dalam Material Requirement Planning (MRP) peneilitian ini dilakukan perhintungan perencanaan pengadaan material dengan 2 metode yaitu metode Silver-Meal dan metode Part-Period Balancing untuk informasi jumlah lot 16 material didapat dari MRP menggunakan metode Lot-for-lot, lot tersebut menjadi dasar pembuatan kombinasi periode pemesanan yang menjadi input dari MRP metode Silver-Meal dan metode Part-Period Balancing. Inventoy cost untuk 9 bulan kedepan dari metode Silver-Meal sebesar Rp 1.097.413.561 yang menjadi inventory cost minimum dibandingkan dengan hasil dari metode Part-Period Balancing sebesar Rp 1.097.468.136 dan exsisting perusahaan sebesar Rp 1.492.375.698. Meskipun frekuensi pengiriman metode Silver-Meal lebih tinggi dibanding dengan metode Part-Period Balancing dan metode existing perusahaan namun dengan cara tersebut perusahaan dapat meminimalkan biaya simpan. Sehingga perencanaan kebutuhan bahan baku yang disarankan peneliti untuk perusahaan adalah metode Silver-Meal penghematan metode ini sebesar 35,99\%. 
3. Pada peneilitian ini metode Silver-Meal merupakan metode terpilih inventory cost minimum. Inventoy cost untuk 9 bulan kedepan dari metode Silver-Meal dengan total frekuensi pengiriman material engsel 19 kali pengiriman, material sekrup dan edging 9 kali pengiriman, material kunci dan handel 11 kali pengiriman, material kaca 16 kali pengiriman, material karton box 17 kali pengiriman, material paper sheet amano 31 kali pengiriman, material paper sheet walnut dan MDF 5 kali pengiriman, material partikel board dan hang 7 kali pengiriman, material frame 30 kali pengiriman, material mahkota dan kaki 6 kali pengiriman, dan perekat 16 kali pengiriman.

\section{DAFTAR PUSTAKA}

Abdillah, A. A. (2017) Analisis Penerapan Material Requirement Planning Dalam Perencanaan Persediaan Bahan Baku Berdasarkan Permintaan Pasar Dengan Menggunakan Pendekatan Single Moving Average Dan Single Exponential Smoothing With Linear Trend (Studi pada PT Kharisma Proteindo Ut. Bandar Lampung: Akhmad Afiks Abdillah.

Gasperz, V. (2005) Production Planning and Inventory Control MRP I. Jakarta: Gramedia Pustaka Utama.

Haizer, Jay \& Render, B. (2005) Manajemen Operasi. 7th edn. Jakarta: Salemba Empat.
Khairani, D. S. (2013) Perencanaan dan Pengendalian Produksi. Yogyakarta: Graha Ilmu.

Kumar (2008) Production and Operations Management with Skill Development, Caselets and Cases. New Delphi: New Age International Limited.

Madinah, W. N. (2015) 'Penentuan Metode Lot Sizing Pada Perencanaan Pengadaan Bahan Baku Kikir Dan Mata Bor ( Studi Kasus : PT X, Sidoarjo )', Jurnal Rekayasa dan Manajemen Sistem Industri, 3(3), pp. 505-515.

Mbota, K. W. (2014) 'Perencanaan Persediaan Bahan Baku Dan Bahan Bakar Dengan Dynamic Lot Sizing ( Studi Kasus : PT Holcim Indonesia Tbk, Tuban Plant)', Jurnal Rekayasa dan Manajemen Sistem Industri, 3(1), pp. 178-188.

Poerwanto, H. (2016) Operasi Produksi, Perencanaan Kebutuhan Bahan, 2010.

Prima, D. S. et al. (2014) 'Baku Animal Feedmill Dengan Lot Sizing Berdasarkan Algoritma Wagner-Within Dan Silver-Meal ( StudiKasus : PT . Sierad Produce, Tbk .)', Jurnal Ilmiah Teknik Industri, pp. 896-906.

Rahmadhani, R. D. (2017) Penentuan Metode Forecast Dan Perencanaan Pengadaan Raw Material Di Industri Manufaktur Filter Rokok. Surabaya: Ratih Dewi Ramadhani.

Rahmayanti, Dina \& Fauzan, A. (2013) 'Optimalisasi sistem persediaan bahan baku karet mentah (lateks) dengan metode lot sizing (studi kasus: pt abaisiat raya)', Optimasi Sistem Industri, pp. 317-325.

Subagyo, P. (2002) Forecasting Konsep dan Aplikasi. Jakarta. 
Suhartini, dkk /JISO, Vol. 1, No.1, Desember 2018, 47-55

Halaman ini sengaja dikosongkan 